Reconcile an Appropriate Model for the Occurrence of Periods of Infection with Hepatitis C in the Province of Nineveh - A comparative Study with the Geometric Process Model -

Muthanna Subhi Sulaiman

muthanna.sulaiman@uomosul.edu.iq

College of Computer Science and Mathematics

University of Mosul, Mosul, Iraq

Received on: 17/09/2012

Accepted on: 30/01/2013

\title{
ABSTRACT
}

In this study we are build a model for the intervals of occurrence of viral hepatitis type $\mathrm{C}$ in Nineveh province by using of time-series analysis, and compared with the Geometric process model, and reconcile an adequate model from Box - Jenkins models for that data.

Resulted from the research that the intervals between HIV cases are decreasing Geometric process leading to unpredictability of these cases or configuration predictive function, while the ARIMA models proposed appropriate for the intervals of occurrence of viral hepatitis type $\mathrm{C}$ cases, and through comparison of these models show that ARIMA $(1,1,5)$ model is the best model proposed for these data.

Keywords: time series, ARIMA models, geometric process model, viral hepatitis.

$$
\begin{aligned}
& \text { توفيق نموذج ملائم لفترات حدوث حالات الإصابة بالتهاب الكبد الفيروسي C في محافظة نينوى }
\end{aligned}
$$

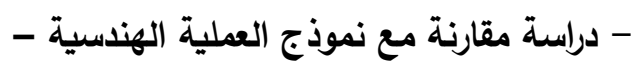

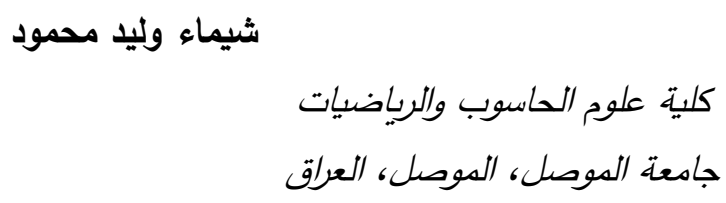

تاريخ قبول البحث: 2013/01/30

تاريخ استلام البحث: 2012/09/17

$$
\begin{aligned}
& \text { الملخص } \\
& \text { تم في هذه الدراسـة بنـاء أنموذج لفترات حدوث حسالات الإصـابة بالتهاب الكبد الفيروسي نوع C في }
\end{aligned}
$$

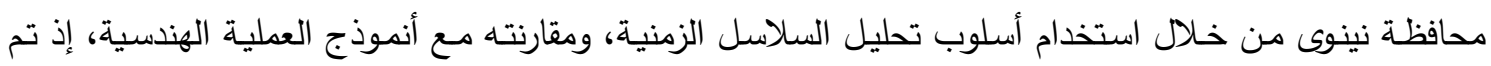

$$
\begin{aligned}
& \text { توفيق أنموذج ملائم لنماذج بوكس - جنكنز لتلك البيانات. } \\
& \text { وقد بين البحث أن فترات حدوث حالات الإصـابة بهذا الفيروس عملية هندسية متناقصة مما يؤدي إلى }
\end{aligned}
$$

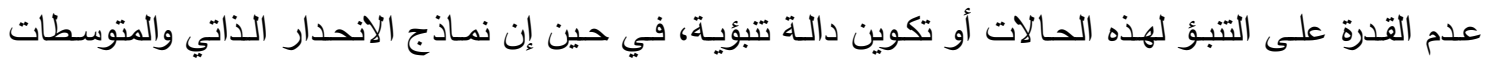

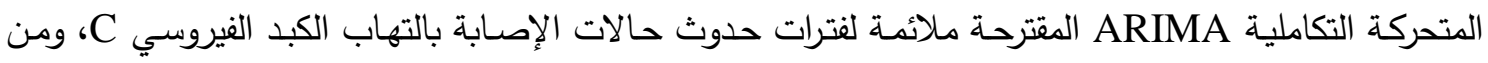

$$
\begin{aligned}
& \text { خلال المقارنة بين هذه النماذج تبين أن أنموذج } \text { ARIMA }(1,1,5 \text { هو أفضل النماذج المقترحة لتلك البيانات. } \\
& \text { الكلمات المفتاحية: السلسلة الزمنية، نماذج ARIMA، أنموذج العملية الهندية، التهاب الكبد الفيروسي. }
\end{aligned}
$$


تُعد السلاسل الزمنية من المواضيع أو الأساليب الإحصائية التي تلاقي اهتماماً كبيراً وواسعاً لدى العديد

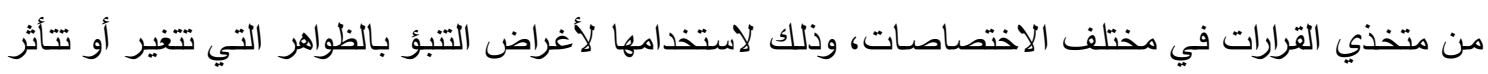
بمرور الزمن. وتعرف بأنها مجموعة من المشاهدات التي تتولد على التوالي خلال الزمن، وتتميز أية سلسلة زمنية

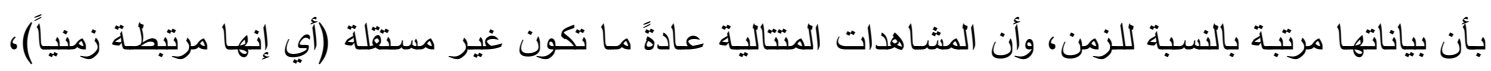

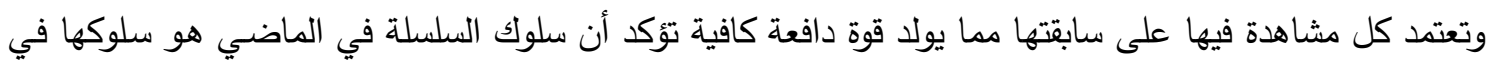

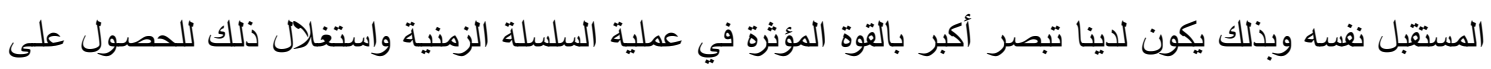

تتبؤات دقيقة [5].

وتعرف السلسلة الزمنية رياضياً بأنها متتابعة من المتغيرات العشوائية معرفـة ضمن فضـاء الاحتماليـة

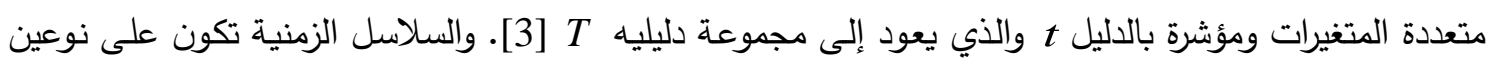

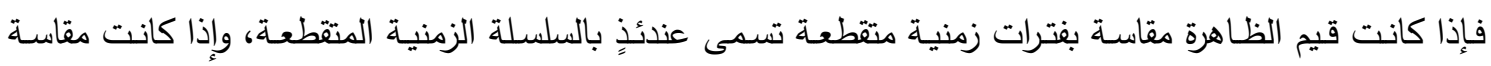
بفترات زمنية مستمرة تسمى عندئذٍ بالسلسلة الزمنية المستمرة [4]. تعد السلاسل الزمنية المتقطعة هي الأكثر شيوعاً في المجال التطبيقي والتي يكون فيها الفترات الزمنية عادة بين مشاهدة وأُخرى متساوية وهذه يمكن الحصول علئية عليها

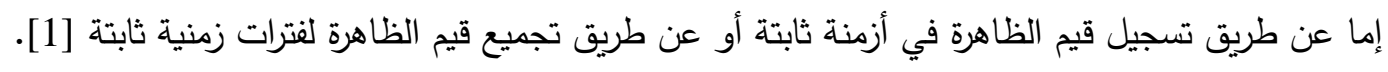

\section{Time Series Analysis}

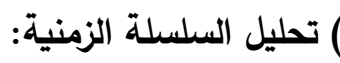

تحليل السلسلة الزمنية هو عملية فصل مكونات السلسلة بعضها عن البعض الأخر ، بهدف تحديد تأثير

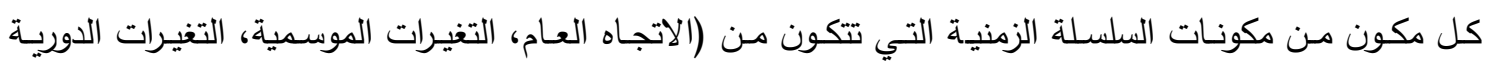
والتغيرات العشوائية) على قيم الظاهرة المدروسة [2]. إن الخطوة الأولى في تحليل أي سلسلة زمنية هي الرسم

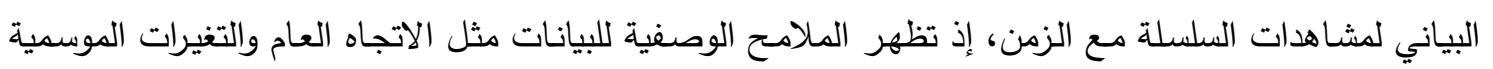

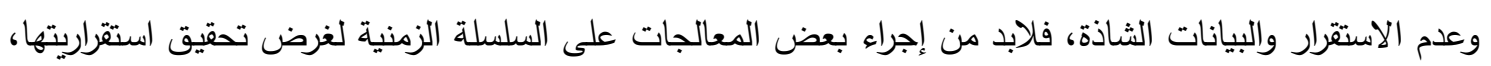

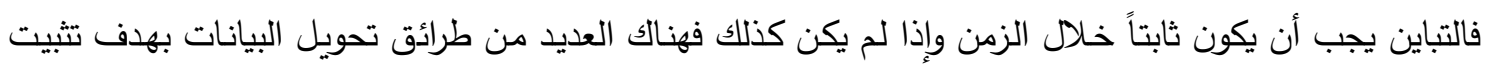
التباين [3]. إن البيانات المحولة تكون عبارة عن دوال حسابية للبيانات الأصلية ومن المهم اختيار التحويل الملائم

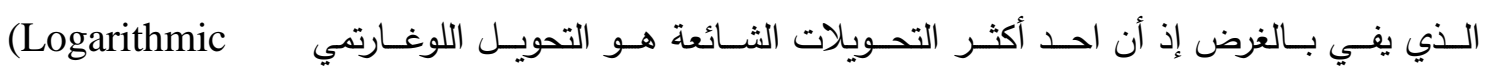
Transformation)

$Z_{t}=\log y_{t}$

إذ أن $Z_{t}$ تمثل السلسلة المحولـة و $y_{t}$ تمثل السلسلة الأصلية. كمـا إن هنـاك تحويلاً أخر هو تحويـل الجذر $Z_{t}=\sqrt{y_{t}}$ التربيعي (Root Square Transformation) ويعبر عنه بالثكل الآتي:

وان هذا النوع من التحويلات يكون غير معروف للقيم السـالبة. ويمكن استخدام تحويلات أُخرى للتوصل إلى

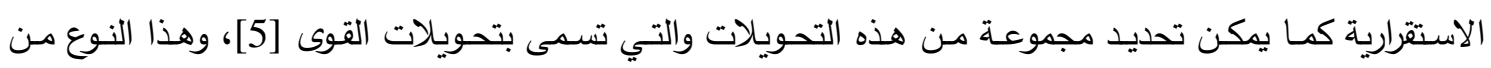
تحويلات Box-Cox يعبر عنه بالثكل الآتي [11]: 


$$
Z_{t}= \begin{cases}\frac{\left(y_{t}+c\right)^{\lambda}-1}{\lambda} & ; \lambda \neq 0 \\ \ln y_{t} & ; \lambda=0\end{cases}
$$

إذ أن $\lambda$ تمثل قيمة القوة في التحويل، و c عبارة عن ثابت. أما الثكل الثاني لعدم استقرارية السلاسل الزمنية فهو

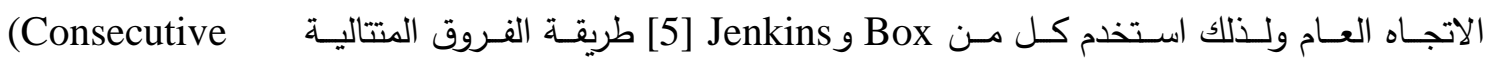
لإزالة الاتجاه العام، وتتكون طريقة الفروق المتتالية من طرح قيم مشاهدات السلسلة

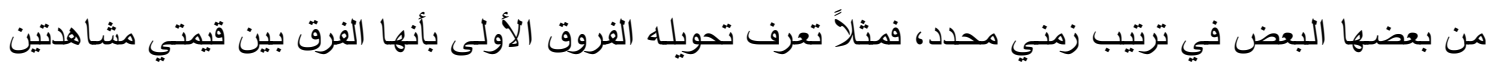
متاليتين $\Delta y_{t}=y_{t}-y_{t-1}$

\section{Correlation in Time Series الارتباط في السلسلة الزمنية:}

عند دراسة السلاسل الزمنية غالباً ما نلجأ إلى حساب عدة دوال منها دالة الارتباط الذاتي ACF ودالة

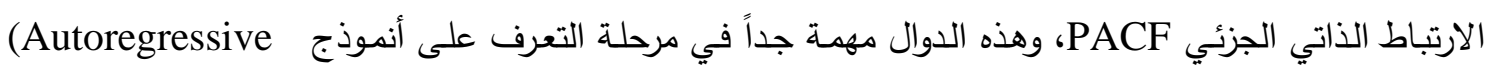
الملائم للسلسلة وهي تقيس العلاقة الإحصائية بين مشاهدات

السلسلة الزمنية الواحدة [13].

(4) منهجية بوكس- جنكنز في السلاسل الزمنية: Box- Jenkins Methodology in Time Series يتضمن أسلوب بوكس جنكنز المتكرر في بناء النماذج الخطية للسلاسل الزمنية أربع خطوات مميزة تم اقتراحها من قبل (Box and Jenkins)، على الرغم من أن منهاج عمل العديد من هذه الخطوات كان معروفاً قبل 1970، إلا أن Box and Jenkins أول من وحد هذه الخطوات في الأسلوب المعروف باسميهما وهي كالآتي

$$
\text { 2- تقدير معالم الأنموذج. }
$$

3- التحقق من صحة الأنموذج.

\section{1- مرحلة التشخيص: The Identification Stage}

تعد مرحلة التثخيص مرحلة أساسية وهامـة في بناء أنموذج السلسلة الزمنية وتتكون من عدة خطوات الرات

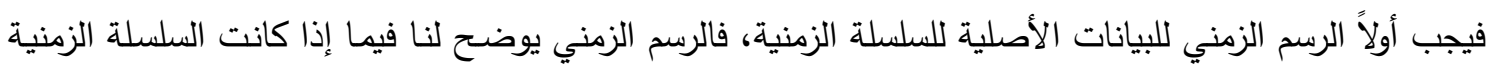

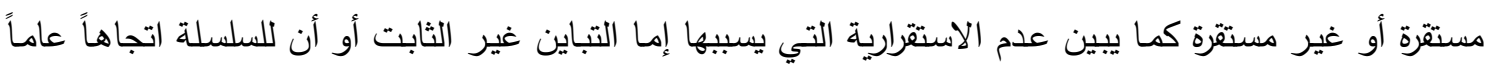

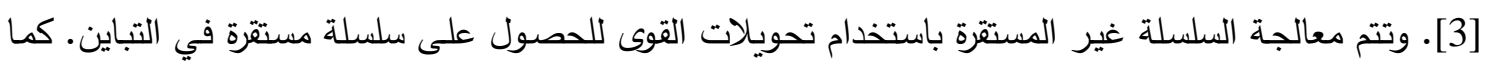

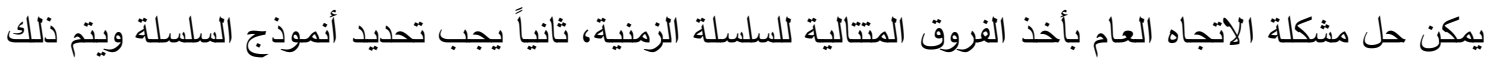

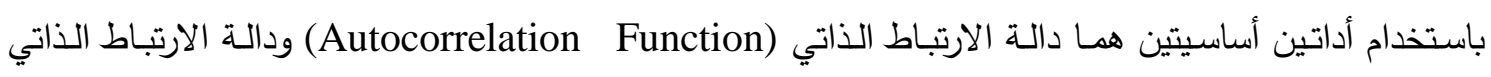
الجزئي (Partial Autocorrelation Function) [11]، وكذلك من خلال استخدام بعض المعايير الإحصائية.

\section{Statistical Criterions}

المعايير الإحصائية:

ظهرت في بداية السبعينات بعض المعايير لتثخيص الأنموذج الملائم للبيانات دون الاعتماد على دوال الارتباط فقط، فقد اقترح العالم الياباني Akaike معياراً يساعد في تحديد رتبة أنموذج السلسلة الزمنية الملائم 
للبيانات كما يمكن استخدامه في مجالات إحصائية أُخرى وتحسب قيمة Akaike Information Criterion كما يأتي [7]:

$\operatorname{AIC}(k)=n \log \left(\hat{\sigma}_{a}{ }^{2}\right)+2 k$

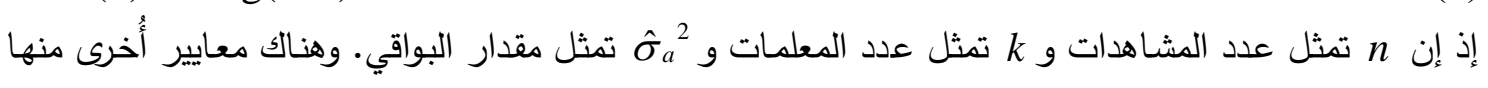

$B I C(k)=n \log \left(\hat{\sigma}_{a}^{2}\right)+k \log (n)$ معيار معلومات بيز BIC ويحسب كما يأتي: $M S E=\frac{1}{n} \sum_{t=1}^{n}\left(y_{t}-\hat{y}_{t}\right)^{2}$

ومعيار متوسط مربعات الخطأ MSE الذي يكون وفق الصيغة الآتية:

ذ إن y $y_{t}$ الأنموذج الأفضل.

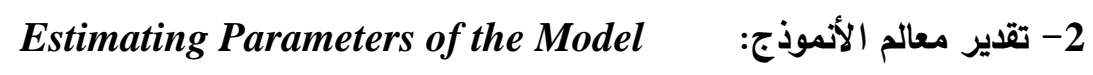

بعد التعرف على أنموذج ARIMA من بين مجموعة يجب تقدير معالم الأنموذج وتستخدم إحدى الطرائق 1- التالية لهذا الغرض [3] وهي:

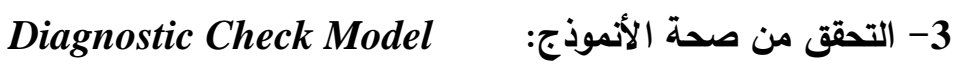

بعد تقدير معلمات الأنموذج نحتاج أولاً لفحص صحة الأنموذج وثانياً هل كل المعلمات المقدرة معنويـة ويمكن تطبيق هذا بواسطة البواقي للأنموذج المقدر .

Forecasting : التكهن:

بعد تحديد الأنموذج المستخدم ودرجته وتقدير معلماته واختبار صحته يصبح الأنموذج جاهزاً للتكهن لقيم

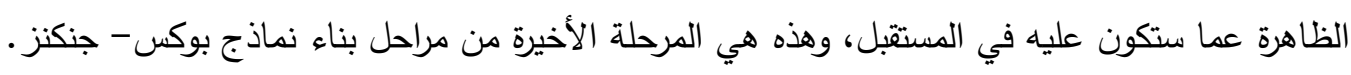
Geometric Process Model (GPM)

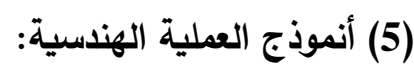
إن فكرة العملية الهندسية GP تعود إلى الباحث [Lam] في عام 1988، إذ يعد أول من قدم العملية

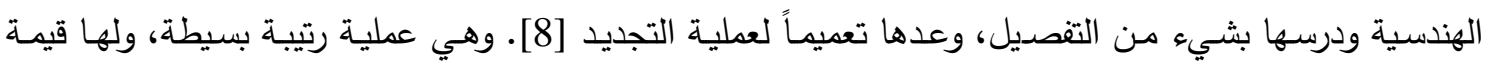
حقيقية a تكون اكبر من الصفر وتمثل نسبة العملية الهندسية التي تقيس قوة واتجاه العملية الهندسية.

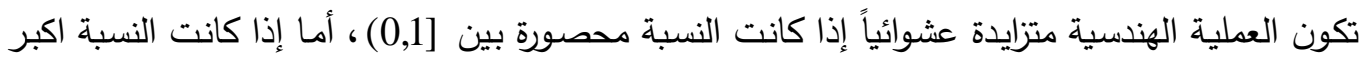
من الواحد فتكون بذلك متتاقصة عشوائياً [10] . ولأنموذج العملية الهندسية معلمات مهمة متمثلة بـ (a) ويمكن تقدير هذه المعلمات وفق الصيخ الآتية [9]: $\hat{a}=\exp \left\{\frac{6}{(n-1) n(n+1)} \sum_{i=1}^{n}(n-2 i+1) \ln X_{i}\right\}$ $\hat{\mu}= \begin{cases}\overline{\hat{X}}_{1} & , \quad a \neq 1 \\ \bar{X} & , \quad a=1\end{cases}$ 
$\hat{\sigma}^{2}= \begin{cases}\frac{1}{n-1} \sum_{i=1}^{n}\left(\hat{X}_{1}-\overline{\hat{X}}_{1}\right)^{2} & , \quad a \neq 1 \\ \frac{1}{n-1} \sum_{i=1}^{n}\left(X_{i}-\bar{X}\right)^{2} & , \quad a=1\end{cases}$

$\hat{X}_{1}=\hat{a}^{i-1} X_{i}$

وللعملية الهندسية دالة تسمى الدالة الهندسية التي تمثل العدد المتوقع للحوادث التي تحدث في الفترة t. وتعود

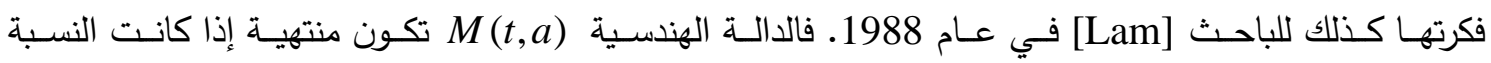

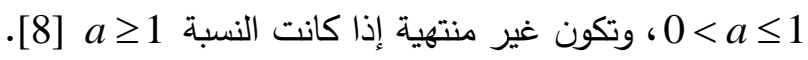

\section{Geometric Process Analysis}

(6) تحليل العملية الهندسية:

في عـام 1992 اقترح العـالم [Lam] تطبيق أربع متتاليات من المتغيرات العشوائية لكي يتمكن من

استخدام جميع المعلومات المعنية في مجموعة البيانات، والتي تكون كالآتي [9]:

$U_{i}=X_{2 i} / X_{2 i-1} \quad, \quad U_{i}^{\prime}=X_{2 i+1} / X_{2 i}$

$V_{i}=X_{i} X_{2 m+1-i} \quad, \quad V_{i}^{\prime}=X_{i+1} X_{2 m+2-i}$

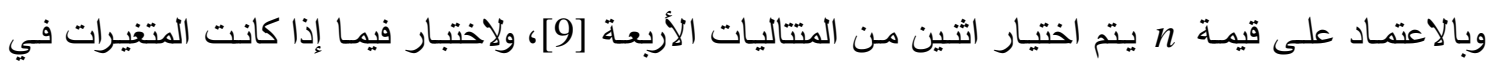
المتتاليات الأربعة مستقلة أم لا، قام بتطبيق اختبار اختلاف الإثارة واختبار نقطة التحول على المتتاليات ويكونان

$$
\begin{aligned}
& D(W)=\left[D_{W}-\frac{m-1}{2}\right] /\left[\frac{m+1}{12}\right]^{1 / 2} \\
& T(W)=\left[T_{W}-\frac{2(m-2)}{3}\right] /\left[\frac{16 m-29}{90}\right]^{1 / 2}
\end{aligned}
$$

وفق الصيخ الآتية [8]:

$P_{T}^{U}=\left\{\begin{array}{l}P(|Z| \geq T(U)) \\ P\left(|Z| \geq T\left(U^{\prime}\right)\right)\end{array} \quad, P_{D}^{U}=\left\{\begin{array}{l}P(|Z| \geq D(U)) \\ P\left(|Z| \geq D\left(U^{\prime}\right)\right)\end{array}\right.\right.$

$P_{T}^{V}=\left\{\begin{array}{l}P(|Z| \geq T(V)) \\ P\left(|Z| \geq T\left(V^{\prime}\right)\right)\end{array} \quad, P_{D}^{V}=\left\{\begin{array}{l}P(|Z| \geq D(V)) \\ P\left(|Z| \geq D\left(V^{\prime}\right)\right)\end{array}\right.\right.$

فإذا كانت اكبر من 0.05، فإن البيانات في هذه الحالة تتبع العملية الهندسية وملائمة لها.

\section{Application}

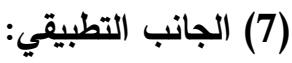

يعد وباء التهاب الكبد الفيروسي نوع C من الأوبئة التي لاقت اهتماماً كبيراً في دول العالم، وهو مرض

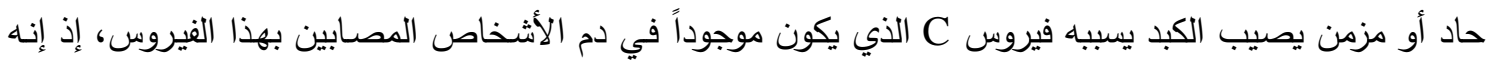

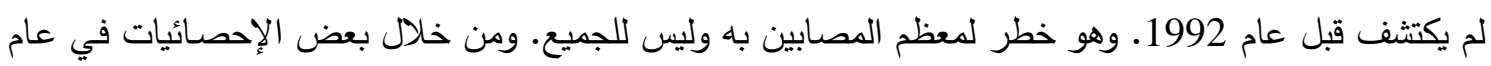
2009 تبين أن هنالك تقريباً (793) مصاباً عراقياً بهذا الفيروس من المتبرعين بالدم على وفق الإحصائية المعدة 
وتضمن الجانب التطبيقي للبحث دراسـة فترات حدوث حالات الإصـابة بالتهاب الكبد الفيروسي C في محافظة نينوى، وعددها 76 فترة وتم أخذها من [6]. فقد تم اختبار هذه البيانات هل تتبع العملية الهندسية أم لا، وعند إجراء الخطوات المبينة في الفقرة (6) وإيجاد قيم P الموضحة فئمات في الجدول الآتي: الجدول (1). قيم P لبيانات التهاب الكبد الفيروسي

\begin{tabular}{||c|c|c|c||}
\hline \hline$P_{T}^{U}$ & $P_{D}^{U}$ & $P_{T}^{V}$ & $P_{D}^{V}$ \\
\hline \hline 0.2380 & 0.1676 & 0.4354 & 0.1676 \\
\hline
\end{tabular}

تبين أن قيم P اكبر من 0.05، مما يدل على أن البيانات تتبع العملية الهندسية. والجدول التالي يمثل تقديرات لمعلمات أنموذج العملية الهندسية: الجدول (2). تقديرات معلمات أنموذج العملية الهندية

\begin{tabular}{|c||c|c|c||c|}
\hline \multirow{2}{*}{ Hepatitis } & \multicolumn{3}{|c||}{ Parameters Estimation } & \multirow{2}{*}{ MSE } \\
\cline { 2 - 4 } & $\hat{a}$ & $\hat{\mu}$ & $\hat{\sigma}^{2}$ & \\
\hline \hline$C$ & 1.0031 & 2.1986 & 1.4814 & 1.1730 \\
\hline
\end{tabular}

من الجدول أعلاه نلاحظ أن قيمة a مبر من الواحد مدا يدل على أنها عملية متتاقصة [10]، وعليه لا يمكن التتبؤ بحالات الإصابة بهذا الفيروس أو تكوين دالة لهم، ولهذا تم المعالجة بتوفيق أنموذج ملائم للفترات باستخدام تحليل السلاسل الزمنية ثم المقارنة بين أنموذج العملية الهندسية وتحليل السلاسل الزمنية وبيان أي الأنموذج الملائم لهذه البيانات. ولدراسة البيانات بتحليل السلسلة الزمنية يجب أولاً رسم السلسلة الزمنية إذ إن الرسم يعطي وصفاً للبيانات ويساعد

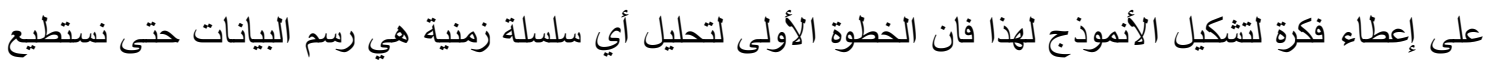
وصف هذه السلسلة ومعرفة سلوكها، فعند رسم بيانات السلسلة كما مبين في الثكل الآتي:

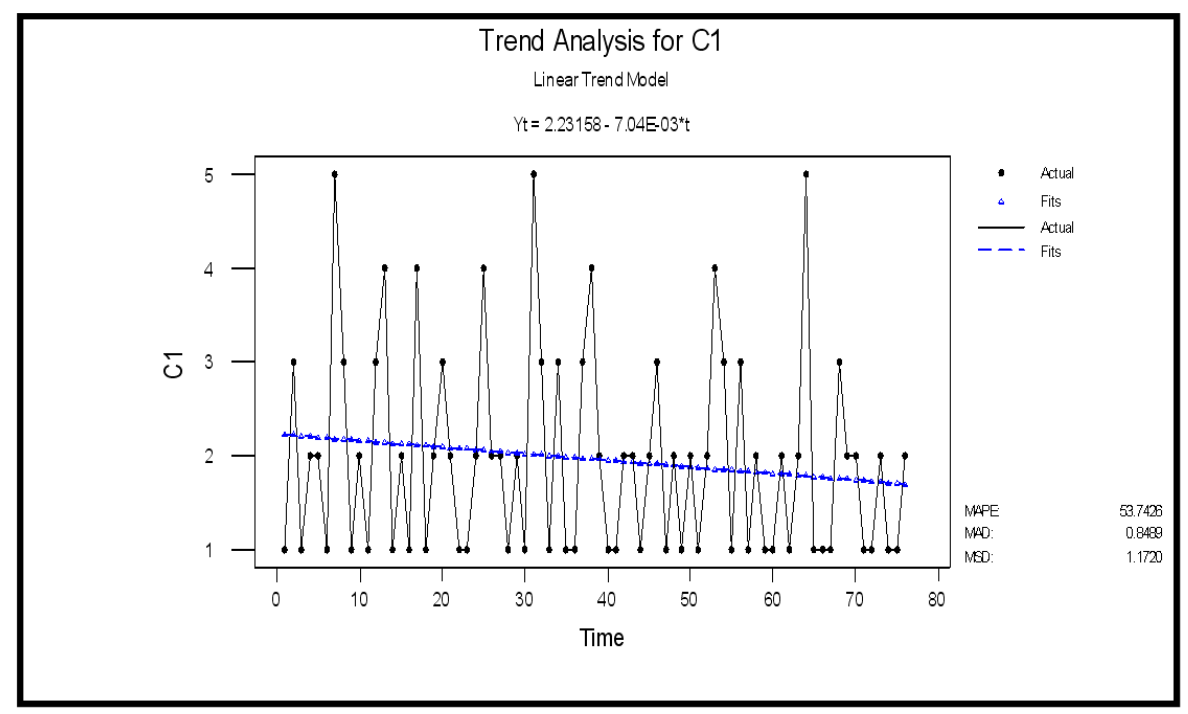

الثكل (1). رسم الاتجاه العام للسلسلة 
إذ تبين وجود تذبذبات مختلفة فيها وهذا يعني أنها غير مستقرة في التباين، كما نلاحظ إن البيانات لا تتوزع حول

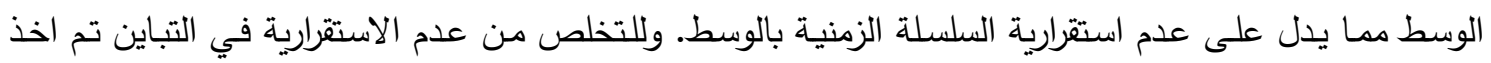
التحويل الجذري للبيانات وبذلك أصبحت السلسلة مستقرة في التباين، وتم اخذ الفرق الأول للتخلص من الاتجاه العام للسلسلة مما أدى إلى استقرارية السلسلة في التباين والوسط كما مبين في الثكل الآتي:

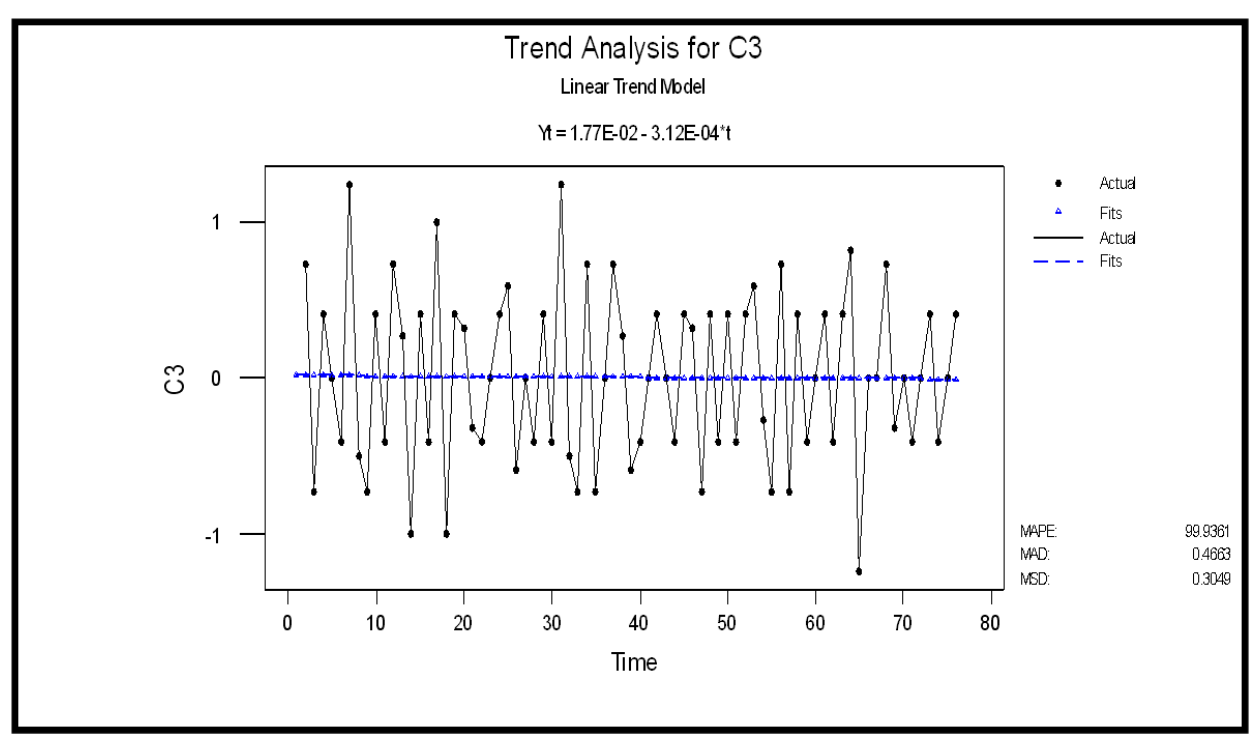

$$
\text { الثكل (2). رسم الاتجاه العام للسلسلة بعد تحويلها إلى مستقرة }
$$

ولتوفيق أفضل أنموذج للسلسلة تم العمل على تحديد الأنموذج الملائم ورتبته من خلال قيم المعايير الإحصائية

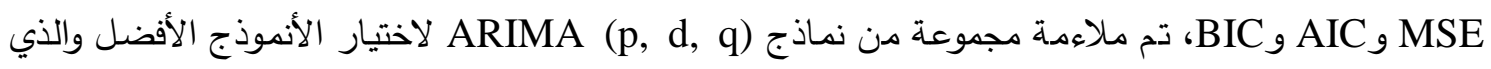
يعطي اقل قيمة للمعايير أعلاه يعد أفضل أنموذج وكما مبين في الجدول الآتي: الجدول (3). قيم المعايير الإحصائية لنماذج ARIMA (p, d, q) للبيانات

\begin{tabular}{|c|c|c|c|}
\hline النماذج|| & MSE & AIC & BIC \\
\hline \hline ARIMA (2,1,5) & $0.11512^{*}$ & -56.41 & -57.2843 \\
\hline ARIMA (4,1,4) & 0.11549 & -54.3125 & -55.3117 \\
\hline ARIMA (1,1,5) & 0.11724 & $-57.8175^{*}$ & $-58.5669^{*}$ \\
\hline ARIMA $(5,1,1)$ & 0.11995 & -57.075 & -57.8244 \\
\hline ARIMA (4,1,3) & 0.12068 & -54.88 & -55.7543 \\
\hline
\end{tabular}

نلاحظ من الجدول أعلاه أن الأنموذج الأفضل هو أنموذج ARIMA $(1,1,5$ AR وذلك لامتلاكه اقل قيمة لمعيار و AIC و PACF المبينة في الثكلين الآتيين: 


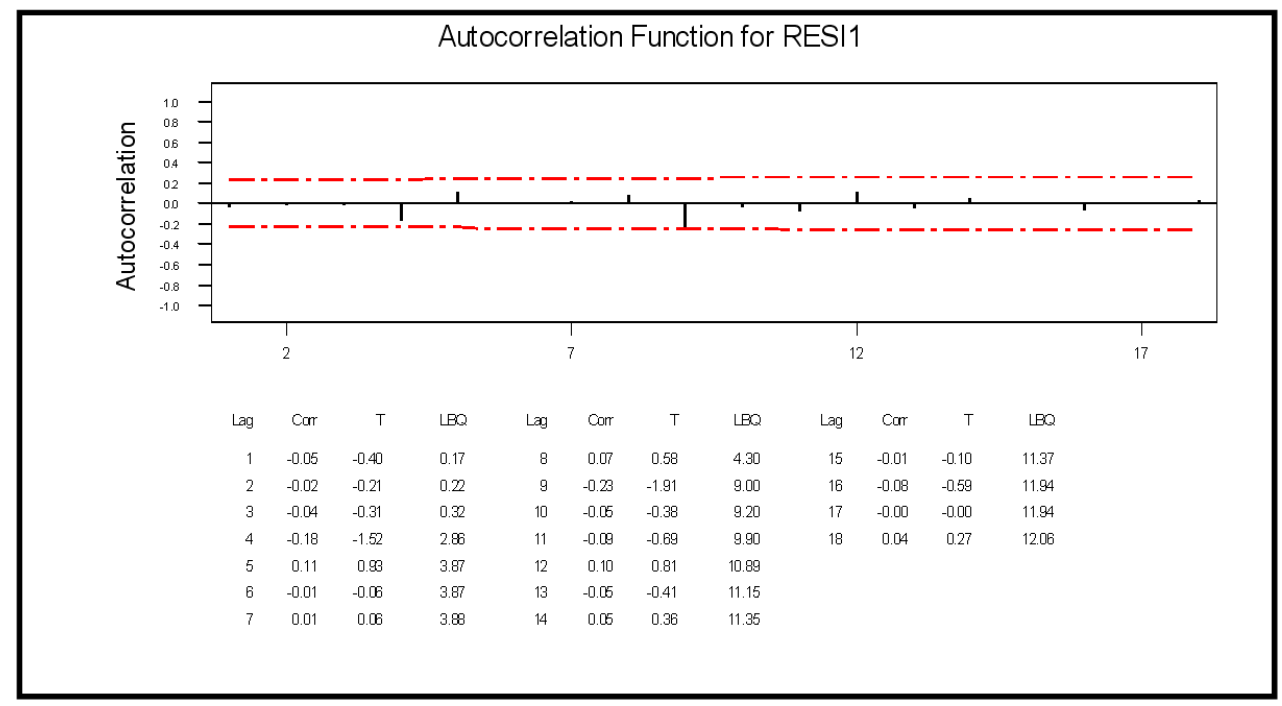

ARIMA (1,1,5) الثكل (3). سلوك دالة الارتباط الذاتي لبواقي أنموذج

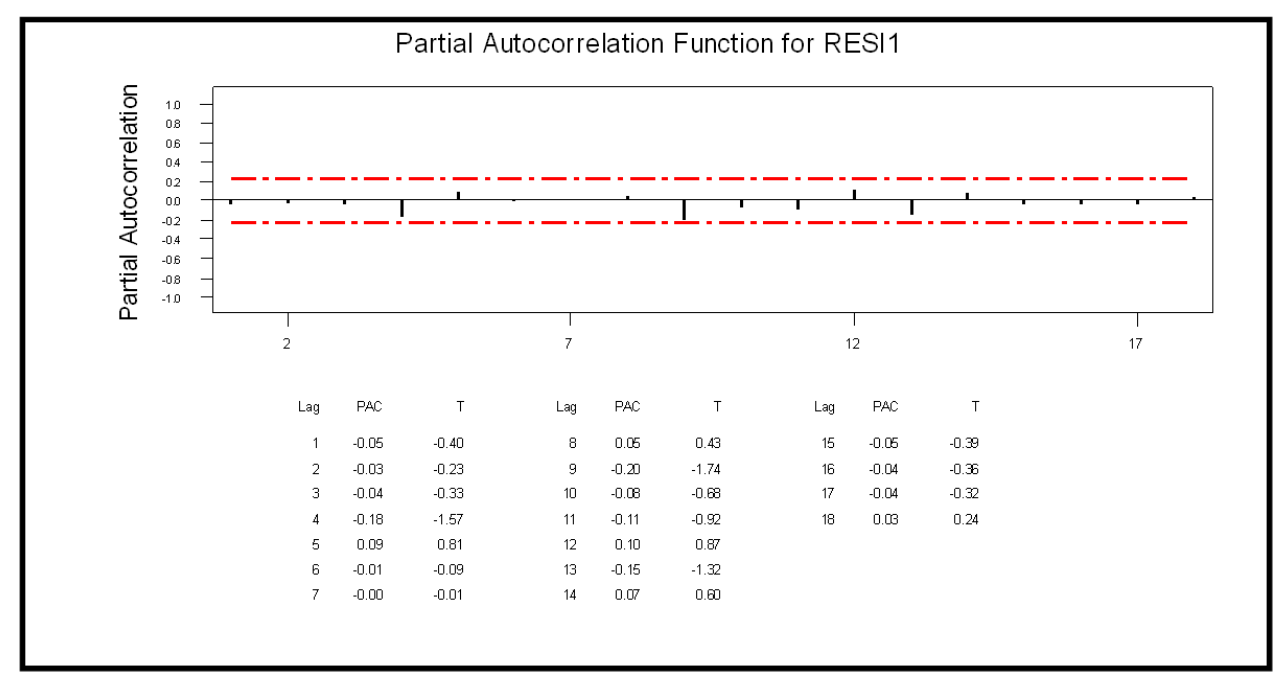

ARIMA (1,1,5) الشكل (4). سلوك دالة الارتباط الذاتي الجزئي لبواقي أنموذج

من الثكلين أعلاه نلاحظ أن جميع الأخطاء تقع ضمن حدود الثقة، مما يشير إلى أن بواقي هذا الأنموذج غير مترابطة مع بعضها البعض أي أن الأخطاء الناتجة من الأنموذج كانت عشوائية تامة. وبذلك فإن الأنموذج النهاء النهائي للبيانات سيكون بالصيغة الآتية:

$$
y_{t}=c+\phi_{1} y_{t-1}-\theta_{1} e_{t-1}-\theta_{2} e_{t-2}-\theta_{3} e_{t-3}-\theta_{4} e_{t-4}-\theta_{5} e_{t-5}+e_{t}
$$
وإن تقديرات معلمات الأنموذج أعلاه مبينة في الجدول الأتي: 
ARIMA (1, 1, 5) الجدول (4). تقديرات معلمات أنموذج

\begin{tabular}{|c|c|c|c|}
\hline Type & Coef & St Dev & T \\
\hline AR(1) & -0.8488 & 0.0996 & -8.52 \\
\hline MA(1) & 0.4493 & 0.1399 & 3.21 \\
\hline MA(2) & .14521 & 0.0246 & 46.62 \\
\hline MA(3) & -0.1964 & 0.1815 & -1.08 \\
\hline MA(4) & -0.3476 & 0.1142 & -3.04 \\
\hline MA(5) & -0.0692 & 0.1272 & -0.54 \\
\hline Constant & -0.004444 & 0.001097 & -4.05 \\
\hline
\end{tabular}

وعليه فإن الأنموذج في المعادلة (16) سيكون وفق الثكل الآتي:

$y_{t}=-0.004444-0.8488 y_{t-1}-0.4493 e_{t-1}-1.1452 e_{t-2}+0.3476 e_{t-4}+e_{t}$

إذ إن الصيغة (17) تمثل الأنموذج الملائم لفترات حدوث حالات الإصسابة بالتهاب الكبد الفيروسي C في محافظة

وقد تم التتبؤ بأبع قيم مستقبلية لفترات حدوث حالات الإصابة بالتهاب الكبد الفيروسي C في محافظة نينوى وكما موضح في الجدول أدناه:

\begin{tabular}{|c|c|c|c|}
\hline \multicolumn{4}{|c|}{ Forecasts from period 76} \\
\hline \multicolumn{4}{|c|}{95 Percent Limits } \\
\hline Period & Forecast & Lower & Upper \\
\hline 77 & 1.47395 & 0.80270 & 2.14520 \\
\hline 78 & 1.34378 & 0.64335 & 2.04422 \\
\hline 79 & 1.26515 & 0.52817 & 2.00213 \\
\hline 80 & 1.25972 & 0.51917 & 2.00027 \\
\hline
\end{tabular}

Conclusions الاستنتاجات: (8)

توصل البحث إلى مجموعة من الاستتتاجات يمكن إجمالها بالنقاط آلاتية:

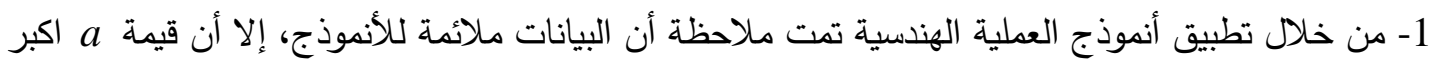

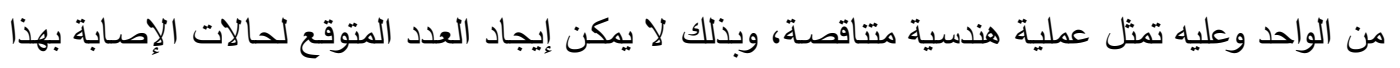

$$
\text { الفيروس كونها دالة هندسية غير منتهية. }
$$

2- من خلال تطبيق منهجية بوكس - جنكنز على البيانات تبين أن الأنموذج الملائم لها هو أنموذج ARIMA

3- من خلال الأنموذج الملائم يمكن التتبؤ بفترات حدوث حالات الإصـابة بهذا الفيروس في محافظة نينوى

عما ستكون عليه في المستقبل.

4- من خلال معيار متوسط مربعات الخطأ MSE تبين أن أنموذج MSIMA (1,1,5 أفضل من أنموذج

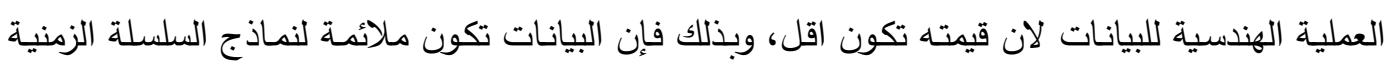

أكثر من أنموذج العملية الهندسية. 


\section{المصادر}

المعدـاري، نـوال محمـود، (2004)، "الـتكهن بواسـطة نمـاذج الاتحـدار الحركـي مـع التطبيـق". رسـالة

ماجستير ، كلية علوم الحاسبات والرياضيات، جامعة الموصل، العرات، العراق.

النعيمي، محمد عبد العال وطعمه، حسن ياسين، (2008)، "الإحصاء التطبيقي". طبعة أولى، دار وائل

$$
\text { للنشر ، عمان - الأردن. }
$$

النعيمي، مروة نبيل، (2010)، "دراسـة السلسـلة الزمنيـة باستخدام تحويلات القوى للمعدلات اليوميـة

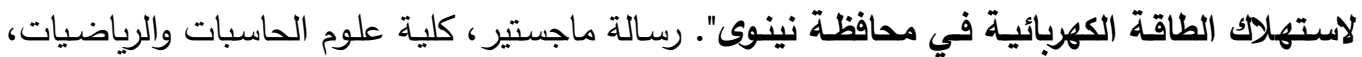

$$
\text { جامعة الموصل، العراق. }
$$

سليمان، انتصار إبراهيم اليأس، (2008)، "التكهن بواسطة نماذج السلاسل الزمنية وإلشبكات العصبية

الاصطناعية ذات التفذية الأمامية مع التطبيق - دراسـة مقارنةة". رسالة ماجستير ، كلية علوم الحاسبات

$$
\text { والرياضيات، جامعة الموصل، العراق. }
$$

فاندل، والتر ، (1992)، "السلاسل الزمنية من الوجهة التطبيقية ونماذج بوكس - جنكنز". تعريب عبد

$$
\text { المرضي حامد عزام، دار المريخ للنشر ، الرياض، المملكة العربية السعودية. }
$$

محمود، شيماء وليد، (2012)، "العمليـة التصـادفية الهندسية وتطبيقاتها في وبـاء التهاب الكبـد

$$
\text { الفيروسي". رسالة ماجستير، كلية علوم الحاسوب والرياضيات، جامعة الموصل، العراق. }
$$

[7] Chatfield C., and Faraway, J. (1998), "Time Series Forecasting with Neural Networks: a Comparative Study Using the Airline Data". Applied Statistics. Vol. 47. Part 2, 231-250.

[8] Lam, Y. (2007), "The Geometric Process and its Applications". World Scientic, Singapore.

[9] Lam, Y. (2008), "Geometric Process". Encyclopedia of Statistical Sciences, John Wiley \& Sons, Inc.

[10] Lam, Y. (2010), "A Geometric Process Maintenance Model". Department of Statistics and Actuarial Science, The University of Hong Kong.

[11] Liu, L.M., (2006), "Time Series Analysis and Forecasting". $2^{\text {nd }}$ ed., Scientific Computing Associates Crop., Illinois, U.S.A.

[12] Liu, L.M. and Lattyak, W.J. (2007), "New and Enhanced Capabilities in Release 8 of the SCA Statistical System ". Illinois: Scientific Computing Associates Crop.

[13] Yaffee, R.A. and McGee, Monnie, (1999), "Introduction to Time Series Analysis and Forecasting with Application of SAS and SPSS". Brooklyn, New York. 